UCRL-ID-117796-Rev-1

ENDL Type Formats for the LLNL Evaluated Atomic Data Library (EADL), Evaluated Electron Data Library (EEDL), and Evaluated Photon Data Library (EPDL)

S. T. Perkins and D. E. Cullen

May 17, 2002

Low

Livermore

National

Laboratory

U.S. Department of Enargy

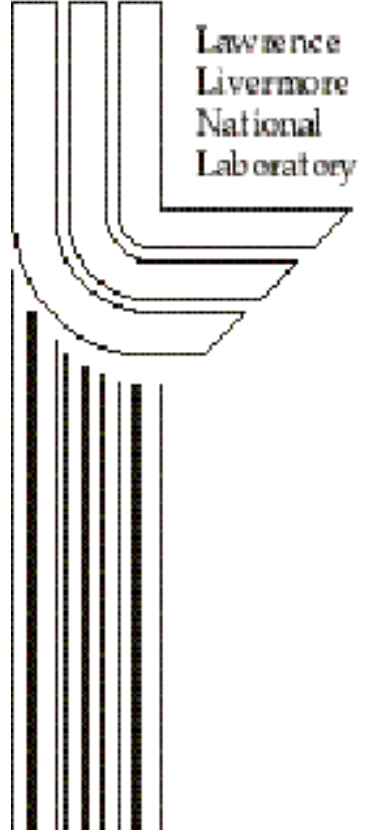




\section{DISCLAIMER}

This document was prepared as an account of work sponsored by an agency of the United States Government. Neither the United States Government nor the University of California nor any of their employees, makes any warranty, express or implied, or assumes any legal liability or responsibility for the accuracy, completeness, or usefulness of any information, apparatus, product, or process disclosed, or represents that its use would not infringe privately owned rights. Reference herein to any specific commercial product, process, or service by trade name, trademark, manufacturer, or otherwise, does not necessarily constitute or imply its endorsement, recommendation, or favoring by the United States Government or the University of California. The views and opinions of authors expressed herein do not necessarily state or reflect those of the United States Government or the University of California, and shall not be used for advertising or product endorsement purposes.

This work was performed under the auspices of the U. S. Department of Energy by the University of California, Lawrence Livermore National Laboratory under Contract No. W-7405-Eng-48.

This report has been reproduced

directly from the best available copy.

Available to DOE and DOE contractors from the

Office of Scientific and Technical Information

P.O. Box 62, Oak Ridge, TN 37831

Prices available from (423) 576-8401

http://apollo.osti.gov/bridge/

Available to the public from the

National Technical Information Service

U.S. Department of Commerce

5285 Port Royal Rd.,

Springfield, VA 22161

http://www.ntis.gov/

OR

Lawrence Livermore National Laboratory

Technical Information Department's Digital Library

http://www.llnl.gov/tid/Library.html 
UCRL-ID-117796, Rev. 1

\title{
ENDL Type Formats for the LLNL Evaluated Atomic Data Library (EADL), Evaluated Electron Data Library (EEDL), and Evaluated Photon Data Library (EPDL)
}

\author{
S. T. Perkins \\ (Posthumously) \\ and \\ Dermott E. Cullen
}

\author{
University of California \\ Lawrence Livermore National Laboratory \\ L-128, P.O. Box 808 \\ Livermore, CA 94550 \\ E.Mail: cullen1@llnl.gov \\ Website: http://www.llnl.gov/cullen1
}

July 1994

Revised: May 2002 


\section{Table of Contents}

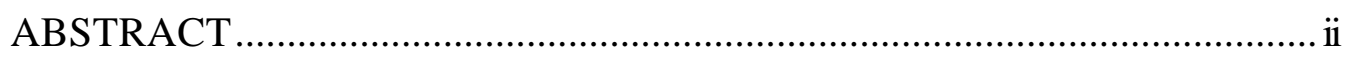

MAY 2002 REVISION ................................................. ii

ACKNOWLEDGEMENT............................................... ii

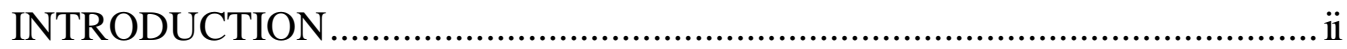

ENDL Type Formats for the Livermore Evaluated Atomic Data Library, EADL 1

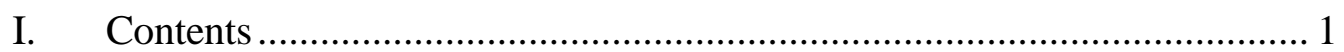

II. Formats and Definitions for the EADL Parameters .................................. 2

III. Definitions and Formats for the EADL Data Lines and Sorting Order..... 4

IV. Atomic Subshell Designators ................................................................. 6

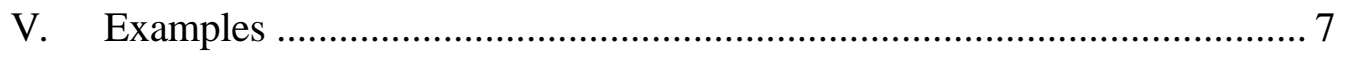

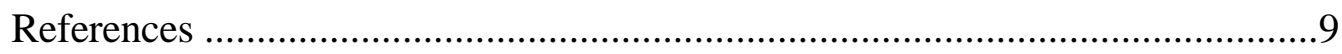

ENDL Type Formats for the Livermore Evaluated Electron Data Library, EEDL 1

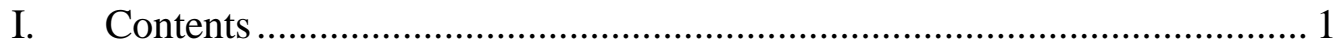

II. Formats and Definitions for the EEDL Parameters.................................. 2

III. Definitions and Formats for the EEDL Data Lines and Sorting Order ..... 4

IV. Atomic Subshell Designators ................................................................. 6

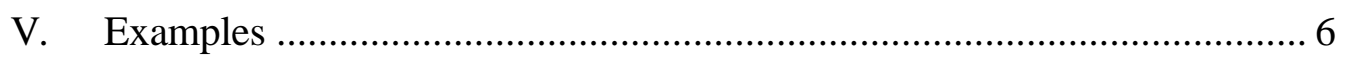

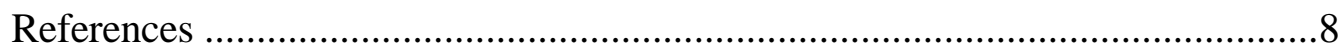

ENDL Type Formats for the Livermore Evaluated Photon Data Library, EPDL 1

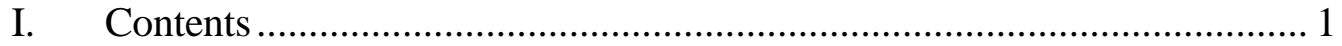

II. Formats and Definitions for the EPDL Parameters .................................. 2

III. Definitions and Formats for the EPDL Data Lines and Sorting Order ..... 5

IV. Atomic Subshell Designator ..................................................................... 6

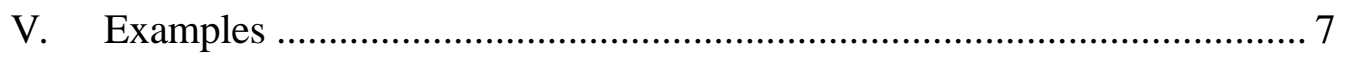

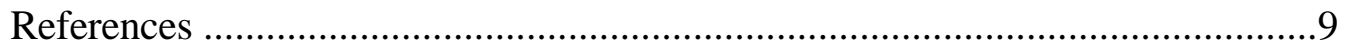




\title{
ENDL Type Formats for the LLNL Evaluated Atomic Data Library (EADL), Evaluated Electron Data Library (EEDL), and Evaluated Photon Data Library (EPDL)
}

\begin{abstract}
The character file formats for the Lawrence Livermore National Laboratory evaluated atomic relaxation library (EADL), the electron library (EEDL), and the photon library (EPDL) are given in this report.

\section{MAY 2002 REVISION}

The May 2002 revision was published after the death of the author S.T. Perkins. However, since most of the contents of this report are still those originally produced by S.T. Perkins, he is still listed as an author posthumously. All revisions to this report are identified in red.
\end{abstract}

\section{ACKNOWLEDGEMENT}

Dermott E. Cullen acknowledges the contribution of Neal Carron who, along with others, emphasized the need for continuing, current documentation of the ENDL data format, including an updated version of this report. The original version of this report was lost; all we had left was a poor PDF version scanned from a copy of the original report, which made it impossible for us to update it. In recent years numerous users have asked for improved and/or updated copies of this report, but due to cutbacks in support, I've never had the time to revisit this report. When Neal Carron wanted an improved copy of this report and I pointed out the lack of available manpower, he volunteered to prepare the original report in Microsoft Word format to facilitate its revision and updating to the current version that you see here.

I was very impressed by Neal's actions. There are many, many people who are willing to freely use our data, code and documentation, and are more than ready to complain if these do not meet their needs. But few are willing to invest their time to help us in our task of preparing data, codes, and documentation for distribution. In this case Neal made a very valuable contribution to our efforts, which I thanks him for, as should all users of this report.

\section{INTRODUCTION}

For many years Lawrence Livermore National Laboratory has published extensive compilations of its nuclear and atomic data bases for neutron and photon interaction data. Starting in 1989 the scope of these data bases was extended from photon interaction data to data that is coupled to photon interactions, namely electron interaction data and atomic relaxation data. These are specifically the evaluated atomic relaxation data library, 
EADL, the evaluated electron interaction data library, EEDL, and the evaluated photon interaction data library, EPDL. All of these libraries span atomic numbers, Z, from 1 to 100. Additionally the particle interaction libraries cover the incident particle energy range from $10 \mathrm{eV}$ to $100 \mathrm{GeV}$. The 1997 release of EPDL (EPDL97) extended the incident photon energy range down to $1 \mathrm{eV}$.

The purpose of these libraries is to furnish data for particle transport calculations. Thus the files have been released for external distribution in a machine independent character format. In a complete coupled electron-photon transport analysis, results from all three of the data files are required. Therefore it is reasonable to discuss the formats for all three libraries in the same work: that is the approach taken here. This report is composed of three sections, each section describing one of the libraries. For ease of reading, each section is separate and unique unto itself, including its own table numbers and references. This report will accompany any request for copies of these evaluated data libraries.

This report and these three data libraries are available from the data centers at Brookhaven National Laboratory, RSIC (Oak Ridge National Laboratory), OECD/NEA Data Bank (France), and IAEA (Vienna). This report and these three data libraries are now available on-line through the IAEA (Vienna) at the website:

http://www-nds.iaea.org/epdl97/ 


\section{ENDL Type Formats for the Evaluated Atomic Data Library (EADL)}

\section{Contents}

This report describes the input formats for the Lawrence Livermore Evaluated Atomic Data Library, EADL. Tables and graphs of these data have been reported in ref. (1). These formats are an extension of the ENDL concepts which form the basis for Lawrence Livermore National Laboratory's evaluated data libraries ${ }^{2}$.

This library contains atomic relaxation information for use in particle transport analysis for $\mathrm{Z}=1-100$ and for each subshell. Units are $\mathrm{cm}$ and $\mathrm{MeV}$ (millions of electron volts). The specific data are the following:

1) Subshell data,

a) number of electrons,

b) binding and kinetic energy $(\mathrm{MeV})$,

c) average radius (cm),

d) radiative and nonradiative level widths $(\mathrm{MeV})$,

e) average number of released electrons and $\mathrm{x}$-rays,

f) average energy of released electrons and $\mathrm{x}$-rays $(\mathrm{MeV})$,

g) average energy to the residual atom, i.e., local deposition (MeV).

2) Transition probability data

a) radiation transition probabilities,

b) nonradiative transition probabilities.

3) Whole atom data,

a) form factor and scattering function,

b) real and imaginary anomalous scattering factors.

As described above, atom data was included in the original release of EADL, but it is no longer included in EADL. This data is currently only used with our Evaluated Photon Data Library (EPDL97), and as such is now only included in EPDL97 (see, the description of EPDL97 later in this report). They are still described here just in case someone wishes to reference or use an older EADL version.

In the context of particle transport, the EADL file only contains data for atomic relaxation. In order to perform coupled photon-electron transport calculations, two additional libraries are required. These are the Livermore Evaluated Photon Data Library $(\mathrm{EPDL})^{3}, 4,5,7$, which describes the interaction of photons with matter and the Livermore Evaluated Electron Data Library $(\mathrm{EEDL})^{6}$, which describes the interaction of electrons with matter.

In Section II, formats and definitions for the EADL parameters are given. This is followed in Section III by the definitions, formats, and sorting order for the data in the EADL file. In Section IV, the subshell designators are defined. Finally in Section V, several examples are given. 


\section{Formats and Definitions for the EADL Parameters}

All data are in the Livermore ENDL (Evaluated Nuclear Data Library) format ${ }^{2}$. Although the ENDL format is much more detailed, in this report only the definitions pertinent to the EADL file are given. The data are in a series of character tables. Each table starts with two header lines that contain the parameters that physically describe the data that follow. The two header lines are followed by a series of data lines, one data point per line. Each table is terminated by an end of table line which is blank except for a 1 in column 72 (column 72 is blank on all other lines in the table). A table may be followed by another table or an end of file.

The two header lines in general in the ENDL format contain a great deal of information. However, as applied to the EADL atomic data the only fields of interest are as shown in Table I.

Table I. Header Line Formats for the EADL Character File

\begin{tabular}{|c|c|c|c|c|}
\hline Line & Columns & Format & Defin & ition \\
\hline 1 & $1-3$ & $\mathrm{I} 3$ & $\mathrm{Z}$ & - atomic number \\
\hline 1 & $4-6$ & I3 & A & - mass number (in all cases $=0$, for elemental data) \\
\hline 1 & $8-9$ & I2 & & - incident particle designator (see Table II) \\
\hline 1 & $11-12$ & I2 & Yo & - outgoing particle designator (see Table II) \\
\hline 1 & $14-24$ & E11.4 & AW & - atomic mass (amu) \\
\hline 1 & $26-31$ & I6 & Date & - date of evaluation (YYMMDD) \\
\hline 2 & $1-2$ & $\mathrm{I} 2$ & $\mathrm{C}$ & - reaction descriptor (see Table II) \\
\hline 2 & $3-5$ & I3 & I & - reaction property (see Table II) \\
\hline 2 & $6-8$ & $\mathrm{I} 3$ & $\mathrm{~S}$ & - reaction modifier (see Table II) \\
\hline 2 & $22-32$ & E11.4 & $\mathrm{X} 1$ & - subshell designator (see Table VI) \\
\hline
\end{tabular}

Table II defines the ENDL parameters that are on the header lines. The actual values for these parameters are what classifies the data in the EADL file.

Table II. Definition of the EADL Parameters

$\begin{array}{rrr}\text { Yi } & -\quad \text { incident particle designator } \\ & =0, \text { no incident particle (in all cases) } \\ \text { C } \quad-\quad & \text { reaction descriptor } \\ & =91, \text { subshell parameters } \\ & =92, \text { transition probabilities } \\ & =93, \text { whole atom parameters (no longer in EADL) } \\ \text { S } \quad-\quad & \text { reaction modifier } \\ & =0, \text { no Xl field data required }\end{array}$


$=91, \mathrm{Xl}$ field data required

$\mathrm{X} 1 \quad$ - value depends upon the value of $\mathrm{S}$

if $S=0, X 1=0$.

if $\mathrm{S}=91, \mathrm{X} 1=$ subshell designator (see Table VI)

Yo - outgoing particle designator

$=0$, no outgoing particle

$=7$, photon

$=9$, electron

I - reaction property

$=912$, number of electrons

$=913$, binding energy

$=914$, kinetic energy

$=915$, average radius

$=921$, radiative level width

$=922$, nonradiative level width

$=931$, radiative transition probability

$=932$, nonradiative transition probability

$=933$, particles per initial vacancy

$=934$, energy of particles per initial vacancy

$=935$, average energy to the residual atom, i.e., local

deposition, per initial vacancy

$=941$, form factor (no longer in EADL)

$=942$, scattering function

$=943$, imaginary anomalous scattering factor

=944, real anomalous scattering factor

In Table III, a summary of the contents of the EADL file is given in terms of the EADL parameters.

Table III. Summary of the EADL Data Base

\begin{tabular}{|c|c|c|c|c|c|c|}
\hline Yi & $\mathrm{C}$ & S & $\mathrm{X} 1$ & Yo & I & Data Types \\
\hline \multicolumn{7}{|c|}{ Subshell parameters } \\
\hline 0 & 91 & 0 & 0 & 0 & 912 & number of electrons \\
\hline 0 & 91 & 0 & 0 & 0 & 913 & binding energy \\
\hline 0 & 91 & 0 & 0 & 0 & 914 & kinetic energy \\
\hline 0 & 91 & 0 & 0 & 0 & 915 & average radius \\
\hline 0 & 91 & 0 & 0 & 0 & 921 & radiative level width \\
\hline 0 & 91 & 0 & 0 & 0 & 922 & nonradiative level width \\
\hline \multicolumn{7}{|c|}{ Transition probabilities } \\
\hline 0 & 92 & 0 & 0 & 0 & 935 & $\begin{array}{l}\text { average energy to the residual } \\
\text { atom, i.e., local deposition, } \\
\text { per initial vacancy }\end{array}$ \\
\hline
\end{tabular}




\begin{tabular}{|c|c|c|c|c|c|c|c|}
\hline 0 & 92 & 0 & 0 . & 7 & or 9 & 933 & \multirow{4}{*}{$\begin{array}{l}\text { average number of particles } \\
\text { per initial vacancy } \\
\text { average energy of particles } \\
\text { per initial vacancy } \\
\text { radiative transition } \\
\text { probability } \\
\text { nonradiative transition } \\
\text { probability }\end{array}$} \\
\hline 0 & 92 & 0 & 0 . & 7 & or 9 & 934 & \\
\hline 0 & 92 & 91 & $\star$ & & 7 & 931 & \\
\hline 0 & 92 & 91 & $\star$ & & 9 & 932 & \\
\hline & \multicolumn{7}{|c|}{ Whole atom parameters (no longer in EADL) } \\
\hline 0 & 93 & 0 & 0 & & 0 & 941 & \multirow{4}{*}{$\begin{array}{l}\text { form factor } \\
\text { scattering function } \\
\text { imaginary anomalous scattering } \\
\text { factor }\end{array}$} \\
\hline 0 & 93 & 0 & 0 . & & 0 & 942 & \\
\hline 0 & 93 & 0 & 0 . & & 0 & 943 & \\
\hline 0 & 93 & 0 & 0 . & & 0 & 944 & \\
\hline
\end{tabular}

* See Table VI

\section{Definitions and Formats for the EADL Data Lines and Sorting Order}

The definitions for the data lines are described in Table IV, followed by their formats in Table V. This is followed by the sorting order of all of the data in the file.

The general ENDL data format defines some 35 types of reaction properties and is used to describe neutron, charged particle, photon, electron, positron, and atomic relaxation processes. The EADL data definitions are but a small subset of this, as shown here.

\section{Table IV. Definitions of the EADL Data}

\begin{tabular}{lll}
\hline $\mathrm{i}$ & - & subshell designator \\
$\mathrm{j}$ & - & secondary subshell designator \\
$\mathrm{k}$ & - & tertiary subshell designator \\
$\mathrm{N}$ & - & number of electrons \\
$\mathrm{E}_{\mathrm{be}}$ & - & binding energy \\
$\mathrm{E}_{\mathrm{ke}}$ & - & kinetic energy \\
$<\mathrm{r}>$ & - & average radius \\
$\Gamma \mathrm{r}$ & - & radiative level width \\
$\Gamma_{\mathrm{nr}}$ & - & nonradiative level width \\
$\mathrm{f}_{\mathrm{r}}$ & - & radiative transition probability \\
$\mathrm{E}_{\mathrm{r}}$ & - & energy of radiative transition \\
$\mathrm{f}_{\mathrm{nr}}$ & - & nonradiative transition probability b \\
$\mathrm{E}_{\mathrm{nr}}$ & - & energy of nonradiative transition \\
$\mathrm{N}_{\mathrm{p}}$ & - & average number of particles per initial vacancy \\
$\mathrm{E}_{\mathrm{p}}$ & - & average energy of particles per initial vacancy, \\
$\left\langle\mathrm{E}_{\text {loc }}>\right.$ & - & average energy to the residual atom, i.e., local deposition, per initial \\
& & vacancy \\
$\mathrm{x}$ & - & argument for form factor and scattering functionc \\
$\mathrm{F}$ & - & form factor (no longer in EADL)
\end{tabular}




$\begin{array}{lll}\mathrm{S} & - & \text { scattering function } \\ \mathrm{I} & - & \text { imaginary anomalous scattering factor } \\ \mathrm{R} & - & \text { real anomalous scattering factor }\end{array}$

a radiative transition; given a vacancy in subshell $\mathrm{i}$ being filled by an electron from subshell $\mathrm{j}$ resulting in the emission of an $\mathrm{x}$-ray, $\mathrm{E}_{\mathrm{r}}$ being the $\mathrm{x}$-ray's energy.

$\mathrm{b}$ nonradiative transition; given a vacancy in subshell i moving to subshell $\mathrm{j}$ resulting in the emission of an electron from subshell $\mathrm{k}, \mathrm{E}_{\mathrm{nr}}$ being the electron's energy.

c the parameter $x\left(\mathrm{~cm}^{-1}\right)$ is defined by $x=\sin (\theta / 2) / \lambda$, where $\theta$ is the photon scattering angle and $\lambda$ is its wave length.

For a given initial subshell vacancy, the transition probabilities are normalized such that the summation over all radiative transitions, $\mathrm{f}_{\mathrm{r}}$, and all nonradiative transitions, $\mathrm{f}_{\mathrm{nr}}$, is unity. Likewise, for a given initial subshell vacancy, energy conservation insures that the average energy into the free $\mathrm{x}$-rays and electrons, $\mathrm{E}_{\mathrm{p}}$, plus the average local energy deposition, $\left\langle\mathrm{E}_{\mathrm{loc}}>\right.$, equals the subshell binding energy, $\mathrm{E}_{\mathrm{be}}$.

The format for the full ENDL data line is 6E11.4. However, the actual number of fields used (up to 6 maximum) depends explicitly upon the reaction property designator, I. Following each set of data is an end of table line with a 1 in column 72, i.e., format of 71X,I1.

Table V. Actual formats for the EADL Data Lines in Terms of the Reaction Property, I (see Table IV for definitions)

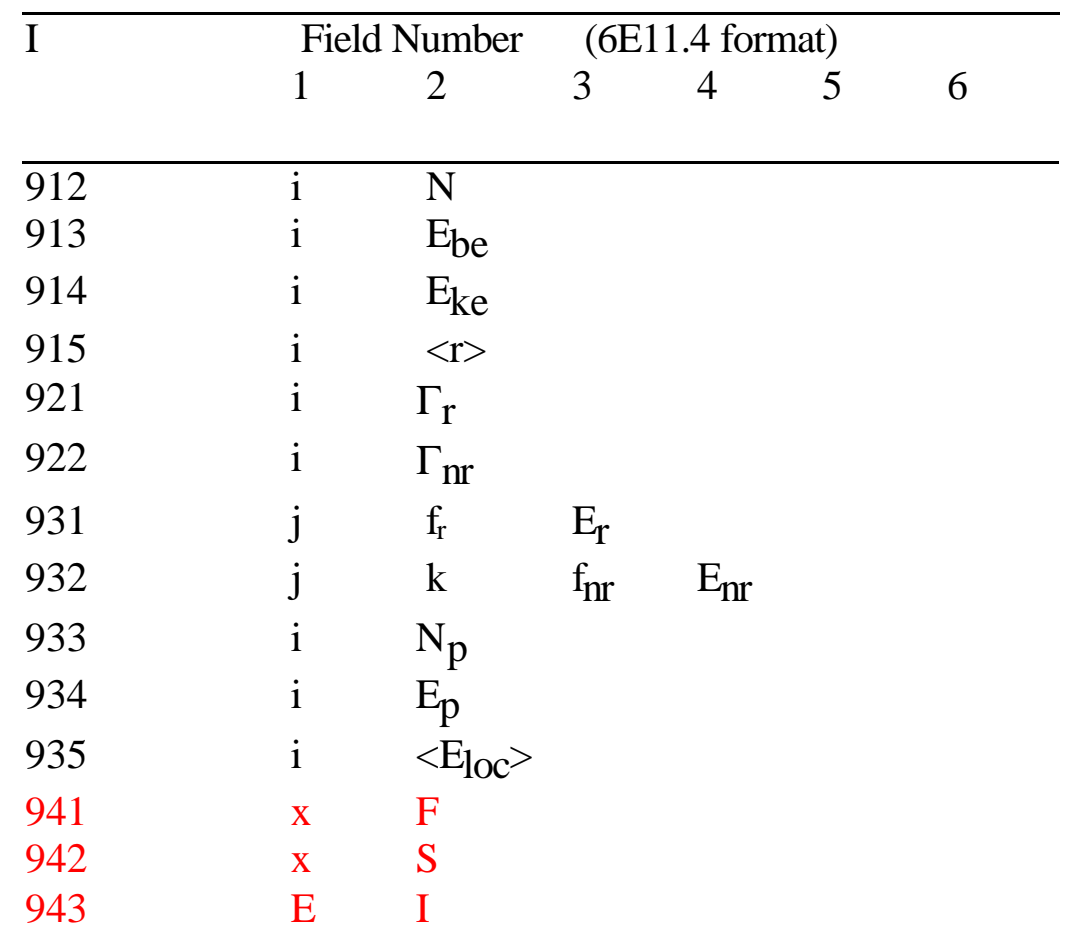


The EADL data is sorted in the following order for the character file:

The data is sorted into ascending order by $\mathrm{Z}(\mathrm{Z}=\mathrm{l}-100)$.

Within each $Z$, data is sorted by increasing $C$ number $(C=91-93$ ), (now $C=91-92$ ).

Within each $C$ number, data is sorted by increasing $S$ number $S=0$ or 91 ).

Within each $S$ number, data is sorted by increasing $X 1$ field (X1=1-61.).

Within each $\mathrm{Xl}$ field, data is sorted by increasing Yo number (Yo=0-9).

Within each Yo number, data is sorted by increasing I number ( $\mathrm{I}=912-944)$, (now $\mathrm{I}=912-935$ ).

Within each data block, data is sorted by increasing field number (see Table V) over all independent variables, i.e., the number of fields required for the data minus one. Field 1 is the slowest varying variable, field 2 the next slowest varying, etc.. For any variable, the sort is by increasing value, e.g., by increasing subshell number.

\section{Atomic Subshell Designators}

Atomic subshells in the ENDL format are specified by prescribed floating point designators. Although this description can specify shells, partial shells, and subshells, only the latter are used in the EADL file. The designators are given in Table VI.

Table VI. Atomic Subshell Designators

\begin{tabular}{|c|c|c|c|c|c|c|c|c|}
\hline $\begin{array}{l}\text { Desig- } \\
\text { nator }\end{array}$ & & Subshell & $\begin{array}{l}\text { Desig- } \\
\text { nator }\end{array}$ & & Subshell & $\begin{array}{l}\text { Desig- } \\
\text { nator }\end{array}$ & & Subshell \\
\hline 1. & $\mathrm{~K}$ & $(1 \mathrm{~s} 1 / 2)$ & 21. & N4 & $(4 \mathrm{~d} 3 / 2)$ & 41. & & $(6 \mathrm{~s} 1 / 2)$ \\
\hline 2. & L & (2) & 22. & N5 & $(4 \mathrm{~d} 5 / 2)$ & 42. & P23 & (6p) \\
\hline 3. & $\mathrm{Ll}$ & $(2 \mathrm{~s} 1 / 2)$ & 23. & N67 & (4f) & 43. & P2 & $(6 \mathrm{p} 1 / 2)$ \\
\hline 4. & L23 & $(2 p)$ & 24. & N6 & $(4 f 5 / 2)$ & 44. & P3 & $(6 \mathrm{p} 3 / 2)$ \\
\hline 5. & L2 & $(2 \mathrm{p} 1 / 2)$ & 25. & N7 & $(4 f 7 / 2)$ & 45. & P45 & (6d) \\
\hline 6. & L3 & $(2 \mathrm{p} 3 / 2)$ & 26. & $\mathrm{O}$ & (5) & 46. & P4 & $(6 \mathrm{~d} 3 / 2)$ \\
\hline 7. & M & (3) & 27. & O1 & $(5 \mathrm{~s} 1 / 2)$ & 47. & P5 & $(6 \mathrm{~d} 5 / 2)$ \\
\hline 8. & Ml & $(3 \mathrm{~s} 1 / 2)$ & 28. & $\mathrm{O} 23$ & $(5 p)$ & 48. & P67 & (6f) \\
\hline 9. & M23 & $(3 p)$ & 29. & $\mathrm{O} 2$ & $(5 \mathrm{p} 1 / 2)$ & 49. & P6 & $(6 \mathrm{f} 5 / 2)$ \\
\hline 10. & M2 & $(3 \mathrm{p} 1 / 2)$ & 30. & $\mathrm{O} 3$ & $(5 \mathrm{p} 3 / 2)$ & 50. & P7 & $(6 f 7 / 2)$ \\
\hline 11. & M3 & $(3 \mathrm{p} 3 / 2)$ & 31. & $\mathrm{O} 45$ & (5d) & 51. & P89 & $(6 \mathrm{~g})$ \\
\hline 12. & M45 & (3d) & 32. & O4 & $(5 \mathrm{~d} 3 / 2)$ & 52. & P8 & $(6 \mathrm{~g} 7 / 2)$ \\
\hline 13. & M4 & $(3 \mathrm{~d} 3 / 2)$ & 33. & O5 & $(5 \mathrm{~d} 5 / 2)$ & 53. & P9 & $(6 \mathrm{~g} 9 / 2)$ \\
\hline 14. & M5 & $(3 \mathrm{~d} 5 / 2)$ & 34. & O67 & (5f) & 54. & P1011 & (6h) \\
\hline 15. & $\mathrm{~N}$ & (4) & 35. & O6 & $(5 f 5 / 2)$ & 55. & P10 & $(6 h 9 / 2)$ \\
\hline 16. & $\mathrm{Nl}$ & $(4 \mathrm{~s} 1 / 2)$ & 36. & $\mathrm{O} 7$ & $(5 f 7 / 2)$ & 56. & P11 & $(6 \mathrm{~h} 11 / 2)$ \\
\hline 17. & $\mathrm{~N} 23$ & $(4 p)$ & 37. & O89 & $(5 g)$ & 57. & Q & (7) \\
\hline 18. & $\mathrm{~N} 2$ & $(4 \mathrm{p} 1 / 2)$ & 38. & O8 & $(5 \mathrm{~g} 7 / 2)$ & 58. & $\mathrm{Ql}$ & $(7 \mathrm{~s} 1 / 2)$ \\
\hline 19. & N3 & $(4 \mathrm{p} 3 / 2)$ & 39. & O9 & $(5 \mathrm{~g} 9 / 2)$ & 59. & Q23 & $(7 p)$ \\
\hline \multirow[t]{2}{*}{20.} & N45 & $(4 d)$ & 40. & $\mathrm{P}$ & (6) & 60. & Q2 & $(7 \mathrm{p} 1 / 2)$ \\
\hline & & & & & & 61. & Q3 & $(7 \mathrm{p} 3 / 2)$ \\
\hline
\end{tabular}




\section{Examples}

In this section, several examples of EADL data are given. These may not coincide with the data in the existing file as improvements are continually being made. As described earlier, the data is in an E11.4 format, with the exception of machine independent modifications made to give more significant figures within the eleven columns. Note also that some of the data lines may have been deleted in order to condense the table to an acceptable size.

The first example is for subshell parameters for neon $(\mathrm{Z}=10)$. There are four tables here. The first table is the number of electrons, the second table is the binding energy, the third table is the kinetic energy, and the last table is the average radius.

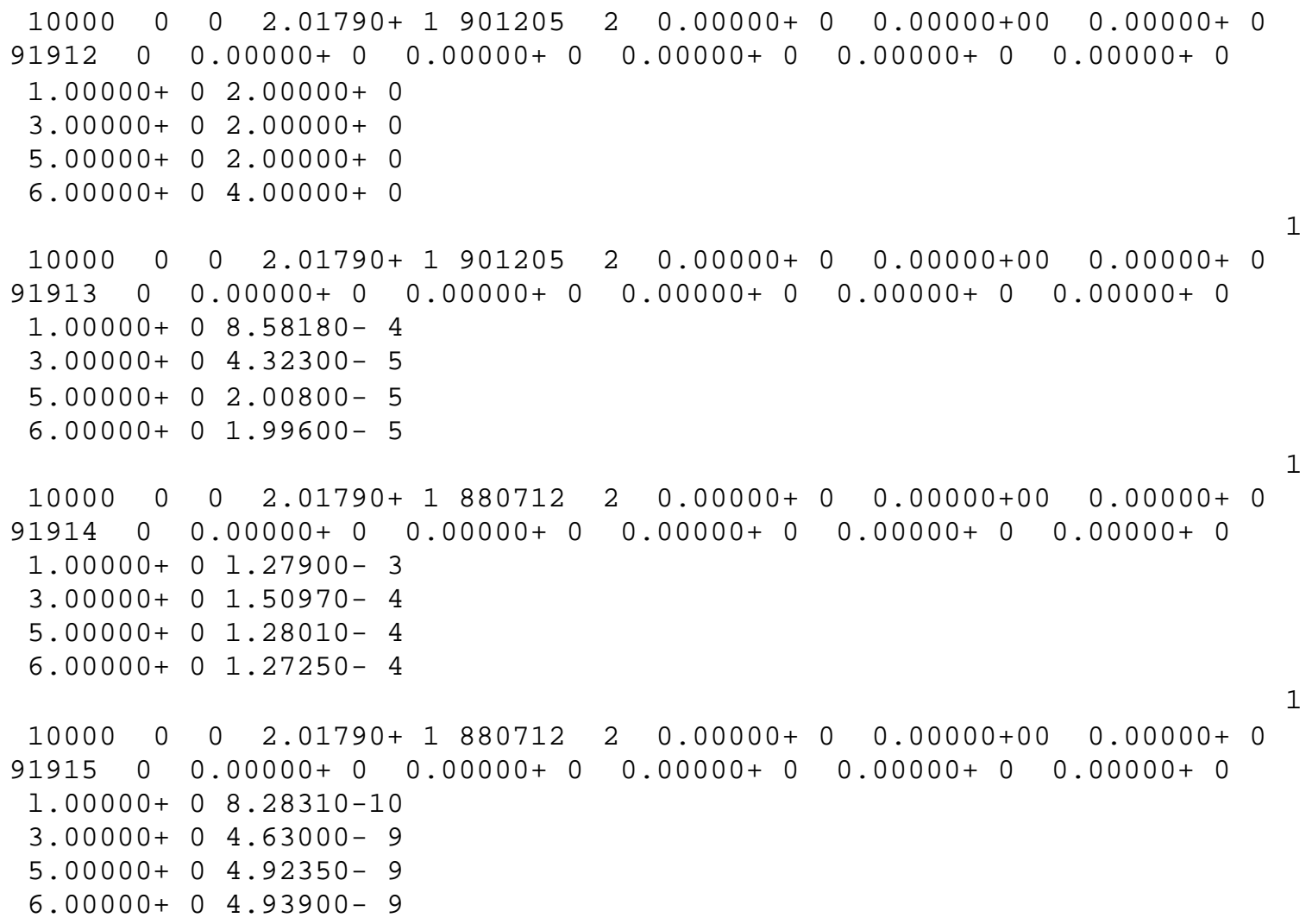

The second example are the radiative and nonradiative transition probabilities from the $\mathrm{K}$ shell of neon $(Z=10)$.

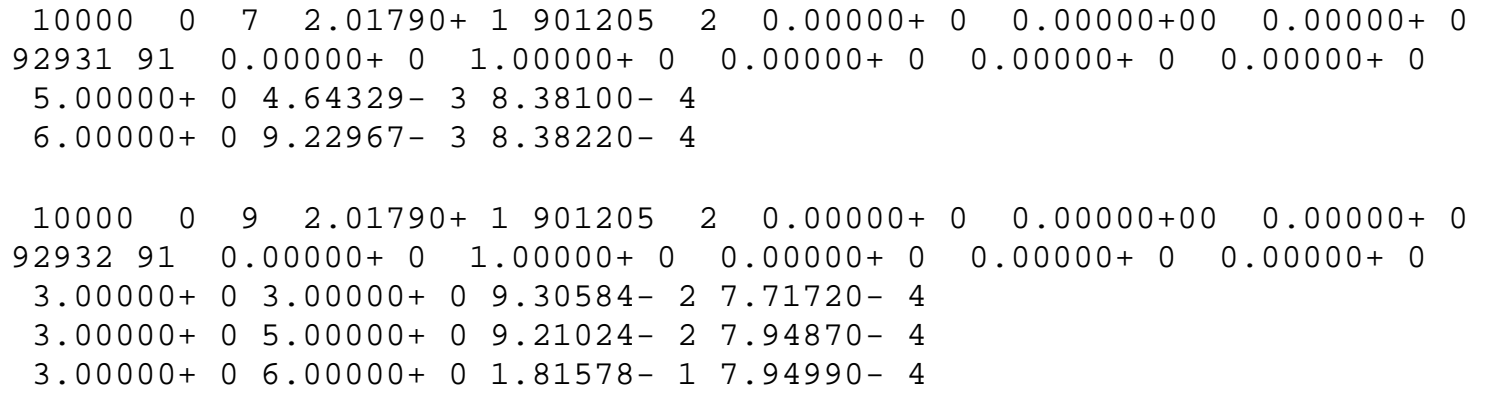

1 
$5.00000+05.00000+01.45681-28.18020-4$

$5.00000+06.00000+03.85131-18.18140-4$

$6.00000+06.00000+02.19689-18.18260-4$ 


\section{References}

1) S. T. Perkins, et. al., Tables and Graphs of Atomic Subshell and Relaxation Data Derived from the LLNL Evaluated Atomic Data Library (EADL). $Z=1$ - 100), Lawrence Livermore National Laboratory, Livermore, CA, Vol. 30 (1991).

2) R. J. Howerton, et. al., OMEGA, A CRAY 1 Executive Code for LLNL Nuclear Data Libraries, Lawrence Livermore National Laboratory, Livermore, CA, UCRL-50400, Vol. 25 (1983). See specifically Ch. I and II.

3) D. E. Cullen, et. al., Tables and Graphs of Photon-Interaction Cross Sections Derived from the LLNL Evaluated Photon Data Library (EPDL). $Z=1-50)$, Lawrence Livermore National Laboratory, Livermore, CA, Vol. 6, Part A, Rev. 4 (1991).

4) D. E. Cullen, et. al., Tables and Graphs of Photon-Interaction Cross Sections Derived from the LLNL Evaluated Photon Data Library (EPDL). Z = 51 - 100), Lawrence Livermore National Laboratory, Livermore, CA, Vol. 6, Part B, Rev. 4 (1991).

5) D. E. Cullen, S. T. Perkins, and J. A. Rathkopf, The 1989 Livermore Photon Data Library (EPDL), Lawrence Livermore National Laboratory, Livermore, CA, UCRLID-103424 (1990.

6) S. T. Perkins, D. E. Cullen, and S. M. Seltzer, Tables and Graphs of Electron Interaction Cross Sections Derived from the LLNL Evaluated Electron Data Library (EEDL), $\mathrm{Z}=1$ - 100), Lawrence Livermore National Laboratory, Livermore, CA, Vol. 31 (1991).

7) D. E. Cullen, J. H. Hubbell, and L. Kissel, EPDL97: the Evaluated Photon Data Library, '97 Version, Lawrence Livermore National Laboratory, UCRL--50400, Vol. 6, Rev. 5, September 1997. 


\section{ENDL Type Formats for the Evaluated Electron Data Library (EEDL)}

\section{Contents}

This report describes the input formats for the Lawrence Livermore Evaluated Electron Data Library, EEDL. Tables and graphs of these data have been reported in ref. (1). These formats are an extension of the ENDL concepts which form the basis for Lawrence Livermore National Laboratory's evaluated data libraries ${ }^{2}$.

This library contains complete information for particle transport for $Z=1-100$ and for incident electron energies from $10 \mathrm{eV}$, or threshold, to $100 \mathrm{GeV}$. Units are barns and $\mathrm{MeV}$ (millions of electron volts). Angular distributions and energy spectra are normalized to unity. The specific data are the following:

1) Elastic transport
a) transport cross section, $\sigma_{\mathrm{el}}(1-<\cos \theta>)$ (b).

2) Large angle elastic scattering (over $\cos \theta=-1$. to 0.999999 )

a) integrated large angle scattering cross section (b),

b) average energy of the scattered electron $(\mathrm{MeV})$,

c) average energy to the residual atom, i.e., local deposition (MeV),

d) angular distribution of the scattered electron.

3) Elastic scattering

a) integrated scattering cross section (b).

4) Ionization (by subshell, over the recoil electron energy range down to $0.1 \mathrm{eV}$ ),

a) integrated cross section (b),

b) average energy of the scattered and recoil electron $(\mathrm{MeV})$,

c) spectra of the recoil electron $\left(\mathrm{MeV}^{-1}\right)$.

5) Bremsstrahlung (over the photon energy range down to $0.1 \mathrm{eV}$ ),

a) integrated cross section (b),

b) average energy of the secondary electron and photon $(\mathrm{MeV})$,

c) spectra of the secondary photon $\left(\mathrm{MeV}^{-1}\right)$.

6) Excitation

a) integrated cross section (b),

b) average energy to the residual atom, i.e., local deposition (MeV).

In the context of particle transport, the EEDL file only contains data for electron transport. In order to perform coupled photon--electron transport calculations, two additional libraries are required. These are the Livermore Evaluated Photon Data Library $(\mathrm{EPDL})^{3}, 4,5,7$, which describes the interaction of photons with matter, and the Livermore Evaluated Atomic Data Library (EADL) ${ }^{6}$, which describes atomic relaxation.

In Section II, formats and definitions for the EEDL parameters are given. This is followed in Section III by the definitions, formats, and sorting order for the data in the 
EEDL file. In Section IV, the subshell designators are defined. Finally in Section V, several examples are given.

\section{Formats and Definitions for the EEDL Parameters}

All data are in the Livermore ENDL (Evaluated Nuclear Data Library) format ${ }^{2}$. Although the ENDL format is much more detailed, in this report only the definitions pertinent to the EEDL file are given. The data are in a series of character tables. Each table starts with two header lines that contain the parameters that physically describe the data that follow. The two header lines are followed by a series of data lines, one data point per line. Each table is terminated by an end of table line which is blank except for a 1 in column 72 (column 72 is blank on all other lines in the table). A table may be followed by another table or an end of file.

The two header lines in general in the ENDL format contain a great deal of information. However, as applied to the EEDL electron data the only fields of interest are as shown in Table I.

Table I. Header Line Formats for the EEDL Character File

\begin{tabular}{|c|c|c|c|}
\hline Line & Columns & Format & Definition \\
\hline 1 & $1-3$ & $\mathrm{I} 3$ & $\mathrm{Z}$ - atomic number \\
\hline 1 & $4-6$ & $\mathrm{I} 3$ & $\begin{array}{l}\text { A - mass number (in all cases }=0 \text {, for } \\
\text { elemental data) }\end{array}$ \\
\hline 1 & $8-9$ & I2 & $\begin{array}{l}\text { Yi - incident particle designator } \\
\text { (see Table II) }\end{array}$ \\
\hline 1 & $11-12$ & I2 & $\begin{array}{l}\text { Yo - out going particle designator } \\
\text { (see Table II) }\end{array}$ \\
\hline 1 & $14-24$ & E11.4 & AW - atomic mass (amu) \\
\hline 1 & $26-31$ & I6 & Date - date of evaluation (YYMMDD) \\
\hline 1 & 32 & I1 & $\begin{aligned} \text { Iflag - interpolation flag } & \\
& =0 \text { or } 2, \text { linear in } \mathrm{x} \text { and } \mathrm{y} \\
& =3 \text {, logarithmic in } \mathrm{x}, \text { linear in } \mathrm{y} \\
& =4, \text { linear in } \mathrm{x} \text {, logarithmic in } \mathrm{y} \\
& =5, \text { logarithmic in } \mathrm{x} \text { and } \mathrm{y}\end{aligned}$ \\
\hline 2 & $1-2^{-}$ & $\overline{\mathrm{I}} 2$ & C - reaction descriptor (see Table II) \\
\hline 2 & $3-5$ & I3 & I - reaction property (see Table II) \\
\hline 2 & $6-8$ & I3 & $\mathrm{S}$ - reaction modifier (see Table II) \\
\hline 2 & $22-32$ & E11.4 & X1 - subshell designator (see Table VI) \\
\hline
\end{tabular}

Table II defines the ENDL parameters that are on the header lines. The actual values for these parameters are what classifies the data in the EEDL file. In what follows, the scattered electron is the incident electron after the reaction. By ENDL convention, this is the one of highest energy. The recoil electron is the other electron involved in the 
reaction. By definition, this is the one of lowest energy. Both of these, along with the photon, are defined as outgoing particles.

\section{Table II. Definition of the EEDL Parameters}

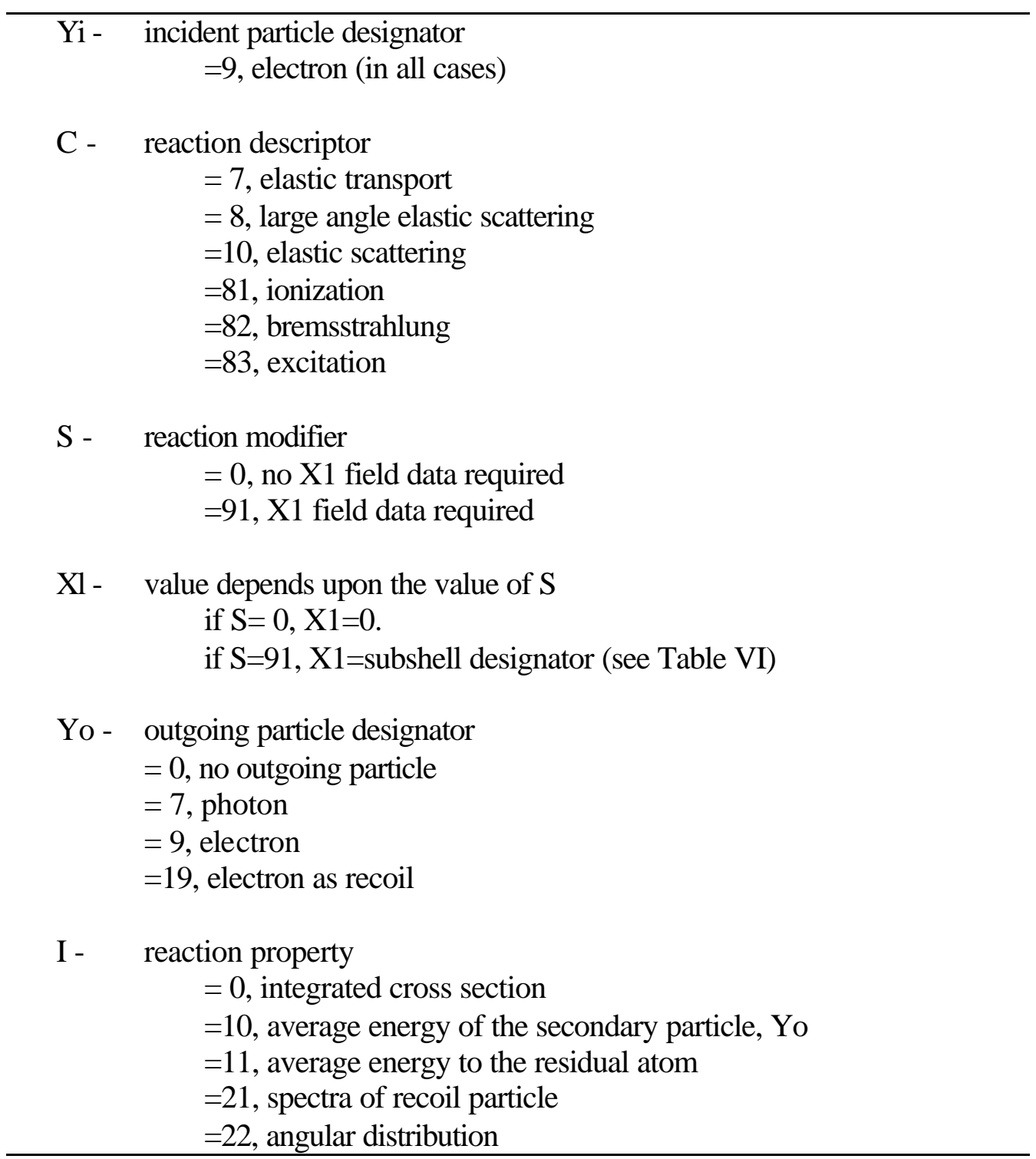

In Table III, a summary of the contents of the EEDL file is given in terms of the EEDL parameters.

Table III. Summary of the EEDL Data Base

\begin{tabular}{lllllll}
\hline & $\mathrm{C}$ & $\mathrm{S}$ & $\mathrm{X} 1$ & Yo & $\mathrm{I}$ & Data
\end{tabular}




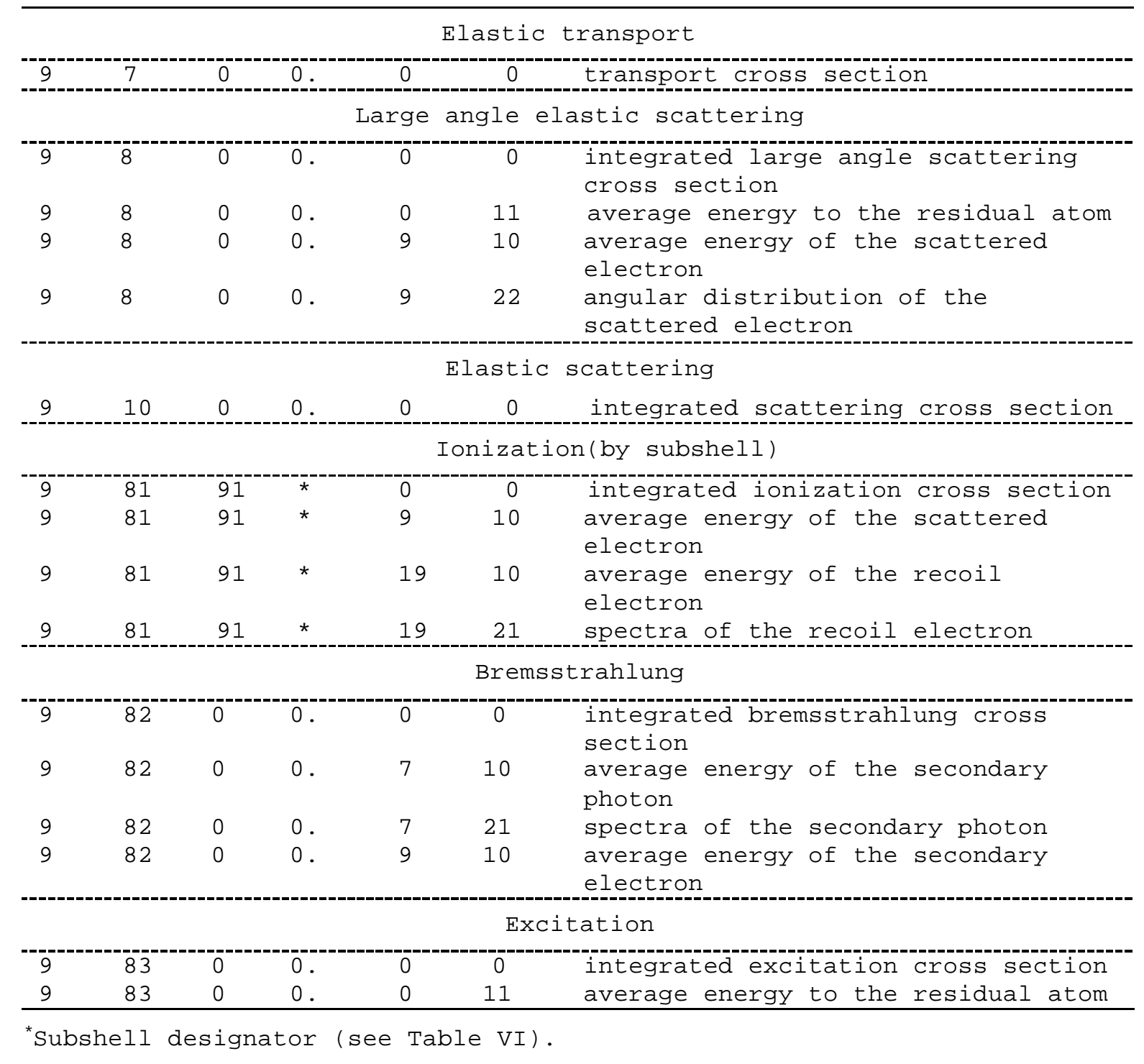

\section{Definitions and Formats for the EEDL Data Lines and Sorting Order}

The definitions for the data lines are described in Table IV, followed by their formats in Table V. This is followed by the sorting order of all of the data in the file.

The general ENDL data format defines some 35 types of reaction properties and is used to describe neutron, charged particle, photon, electron, positron, and atomic relaxation processes. The EEDL data definitions are but a small subset of this, as shown here.

\section{Table IV. Definitions of the EEDL Data}

\begin{tabular}{lll}
\hline $\mathrm{E}$ & - & incident electron energy \\
$\sigma$ & - & cross section \\
$\left\langle\mathrm{E}_{\mathrm{p}}^{\prime}\right\rangle$ & - & average energy of the secondary particle \\
\hline
\end{tabular}




\begin{tabular}{lll}
\hline$\left\langle\mathrm{E}_{\mathrm{loc}}\right\rangle$ & - average energy to the residual atom, i.e., local deposition \\
$\mathrm{E}^{\prime}$ & - & energy of the secondary particle \\
$\mathrm{p}$ & - & particle spectra, unit normalized \\
$\mathrm{x}$ & - & angular variable, $\mathrm{x}=1-\cos \theta$, where $\theta$ is the scattering angle \\
$\mathrm{f}$ & - & angular distribution, unit normalized, over the range \\
& & $\mathrm{x}=0.000001$ to $2 .(\cos \theta=-1$. to 0.999999$)$ \\
\hline
\end{tabular}

By definition for electron scattering, local energy deposition is zero and the average energy to the scattered electron is equal to the energy of the incident electron. These values are carried in the data files so as not to make any special unique cases.

The format for the full ENDL data line is 6E11.4. However, the actual number of fields used (up to 6 maximum) depends explicitly upon the reaction property designator, I. Following each set of data is an end of table line with a 1 in column 72, i.e., format of 71X,I1.

Table V. Actual formats for the EEDL Data Lines in Terms of the Reaction Property, I (see Table IV for definitions)

\begin{tabular}{|c|c|c|c|c|c|c|}
\hline \multirow[t]{2}{*}{$\mathrm{I}$} & \multicolumn{6}{|c|}{ Field Number (6E11.4 format) } \\
\hline & 1 & 2 & 3 & 4 & 5 & 6 \\
\hline 0 & $\bar{E}$ & $\sigma$ & & & & \\
\hline 10 & $\mathrm{E}$ & & & & & \\
\hline 11 & $\mathrm{E}$ & & & & & \\
\hline 21 & $\mathrm{E}$ & $E^{\prime}$ & $\mathrm{p}$ & & & \\
\hline 22 & $\mathrm{E}$ & $\mathrm{x}$ & $\mathrm{f}$ & & & \\
\hline
\end{tabular}

The EEDL data is sorted in the following order for the character file:

The data is sorted into ascending order by $\mathrm{Z}(\mathrm{Z}=\mathrm{l}-100)$.

Within each $\mathrm{Z}$, data is sorted by increasing $\mathrm{C}$ number $(\mathrm{C}=7-83)$.

Within each $C$ number, data is sorted by increasing $S$ number $(S=0$ or 91$)$.

Within each $\mathrm{S}$ number, data is sorted by increasing $\mathrm{X} 1$ field $(\mathrm{X} 1=1 .-61$.$) .$

Within each X1 field, data is sorted by increasing Yo number (Yo=0-19).

Within each Yo number, data is sorted by increasing I number $(\mathrm{I}=0-22)$.

Within each data block, data is sorted by increasing field number (see Table V) over all independent variables, i.e., the number of fields required for the data minus one. Field 1 is the slowest varying variable, field 2 the next slowest varying, etc.. For any variable, the sort is by increasing value, e.g., by increasing incident electron energy. 


\section{Atomic Subshell Designators}

Atomic subshells in the ENDL format are specified by prescribed floating point designators. Although this description can specify shells, partial shells, and subshells, only the latter are used in the EEDL file. The designators are given in Table VI.

Table VI. Atomic Subshell Designators

\begin{tabular}{|c|c|c|c|c|c|c|c|c|}
\hline $\begin{array}{l}\text { Desig- } \\
\text { nator }\end{array}$ & & Subshell & $\begin{array}{l}\text { Desig- } \\
\text { nator }\end{array}$ & & Subshell & $\begin{array}{l}\text { Desig- } \\
\text { nator }\end{array}$ & & ubshell \\
\hline 1. & $\mathrm{~K}$ & $(1 \mathrm{~s} 1 / 2)$ & 21. & N4 & $(4 \mathrm{~d} 3 / 2)$ & 41. & $\overline{\mathrm{Pl}}$ & $(6 \mathrm{~s} 1 / 2)$ \\
\hline 2. & $\mathrm{~L}$ & (2) & 22. & N5 & $(4 \mathrm{~d} 5 / 2)$ & 42. & P23 & $(6 p)$ \\
\hline 3. & $\mathrm{Ll}$ & $(2 \mathrm{~s} 1 / 2)$ & 23. & N67 & $(4 \mathrm{f})$ & 43. & P2 & $(6 \mathrm{p} 1 / 2)$ \\
\hline 4. & L23 & $(2 p)$ & 24. & N6 & $(4 f 5 / 2)$ & 44. & P3 & $(6 \mathrm{p} 3 / 2)$ \\
\hline 5. & L2 & $(2 \mathrm{p} 1 / 2)$ & 25. & N7 & $(4 f 7 / 2)$ & 45. & P45 & (6d) \\
\hline 6. & L3 & $(2 \mathrm{p} 3 / 2)$ & 26. & $\mathrm{O}$ & (5) & 46. & P4 & $(6 \mathrm{~d} 3 / 2)$ \\
\hline 7. & M & (3) & 27. & O1 & $(5 \mathrm{~s} 1 / 2)$ & 47. & P5 & $(6 \mathrm{~d} 5 / 2)$ \\
\hline 8. & Ml & $(3 \mathrm{~s} 1 / 2)$ & 28. & $\mathrm{O} 23$ & $(5 p)$ & 48. & P67 & (6f) \\
\hline 9. & M23 & $(3 p)$ & 29. & $\mathrm{O} 2$ & $(5 \mathrm{p} 1 / 2)$ & 49. & P6 & $(6 f 5 / 2)$ \\
\hline 10. & M2 & $(3 \mathrm{p} 1 / 2)$ & 30. & $\mathrm{O} 3$ & $(5 \mathrm{p} 3 / 2)$ & 50. & P7 & $(6 f 7 / 2)$ \\
\hline 11. & M3 & $(3 \mathrm{p} 3 / 2)$ & 31. & $\mathrm{O} 45$ & $(5 d)$ & 51. & P89 & $(6 g)$ \\
\hline 12. & M45 & (3d) & 32. & O4 & $(5 \mathrm{~d} 3 / 2)$ & 52. & P8 & $(6 \mathrm{gg} / 2)$ \\
\hline 13. & M4 & $(3 \mathrm{~d} 3 / 2)$ & 33. & O5 & $(5 \mathrm{~d} 5 / 2)$ & 53. & P9 & $(6 \mathrm{~g} 9 / 2)$ \\
\hline 14. & M5 & $(3 \mathrm{~d} 5 / 2)$ & 34. & O67 & $(5 f)$ & 54. & P1011 & (6h) \\
\hline 15. & $\mathrm{~N}$ & (4) & 35. & O6 & $(5 f 5 / 2)$ & 55. & P10 & $(6 \mathrm{~h} 9 / 2)$ \\
\hline 16. & $\mathrm{Nl}$ & $(4 \mathrm{~s} 1 / 2)$ & 36. & O7 & $(5 f 7 / 2)$ & 56. & P11 & $(6 \mathrm{~h} 11 / 2)$ \\
\hline 17. & $\mathrm{~N} 23$ & $(4 p)$ & 37. & O89 & $(5 \mathrm{~g})$ & 57. & Q & (7) \\
\hline 18. & $\mathrm{~N} 2$ & $(4 \mathrm{p} 1 / 2)$ & 38. & O8 & $(5 \mathrm{~g} 7 / 2)$ & 58. & $\mathrm{Ql}$ & $(7 \mathrm{~s} 1 / 2)$ \\
\hline 19. & N3 & $(4 \mathrm{p} 3 / 2)$ & 39. & O9 & $(5 \mathrm{~g} 9 / 2)$ & 59. & Q23 & $(7 p)$ \\
\hline \multirow[t]{2}{*}{20.} & N45 & (4d) & 40. & $\mathrm{P}$ & (6) & 60. & Q2 & $(7 \mathrm{p} 1 / 2)$ \\
\hline & & & & & & 61. & Q3 & $(7 \mathrm{p} 3 / 2)$ \\
\hline
\end{tabular}

\section{Examples}

In this section, several examples of EEDL data are given. These may not coincide with the data in the existing file as improvements are continually being made. As described earlier, the data is in an E11.4 format, with the exception of machine independent modifications made to give more significant figures within the eleven columns. Note also that some of the data lines may have been deleted in order to condense the table to an acceptable size.

The first example is for ionization of the $\mathrm{K}$ shell of neon $(\mathrm{Z}=10)$. There are three tables included here. The first is for the cross section, the second is for the average energy to the scattered electron, and the last is for the average energy to the recoil electron.

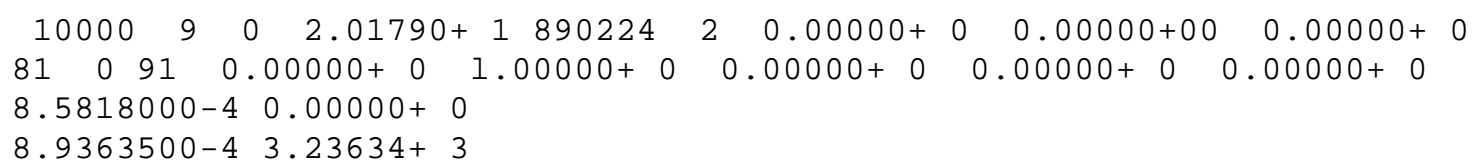




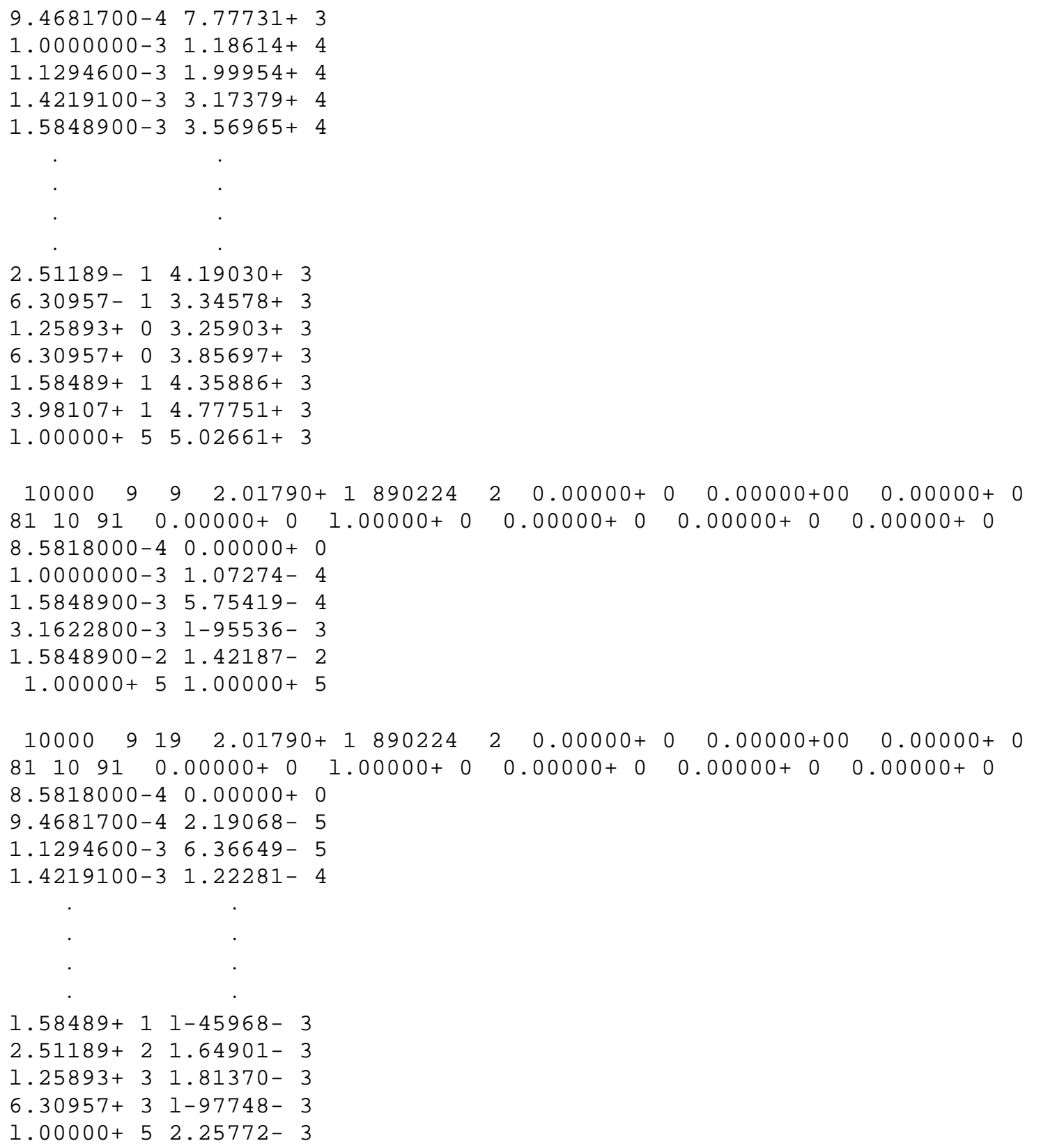

The second example is for Bremsstrahlung in neon $(Z=10)$. Specifically it is for the spectra of emerging photons.

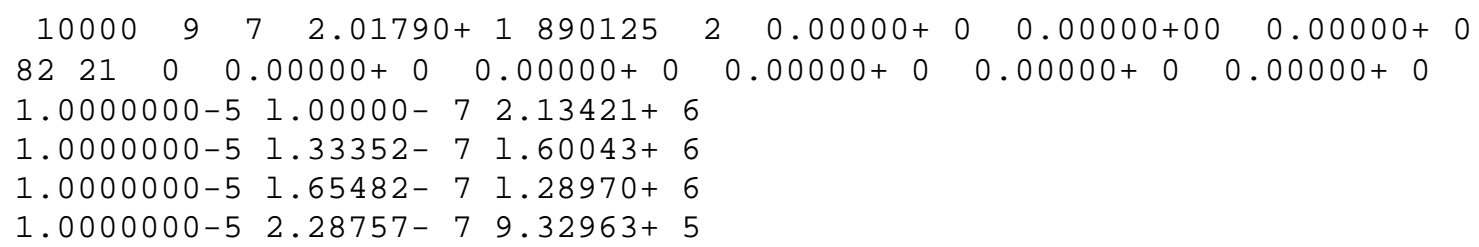




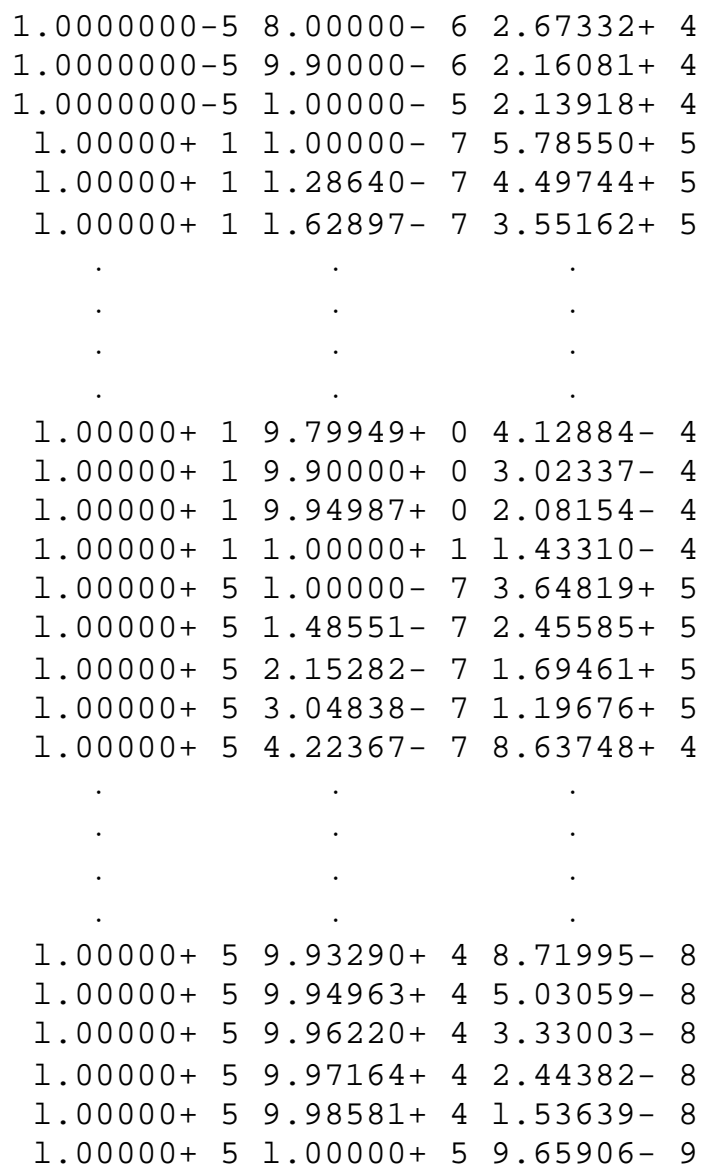

\section{References}

1) S. T. Perkins, D. E. Cullen, and S. M. Seltzer, Tables and Graphs of ElectronInteraction Cross Sections Derived from the LLNL Evaluated Electron Data Library (EEDL), Z = 1 - 100), Lawrence Livermore National Laboratory, Livermore, CA, Vol. 31 (1991).

2) R. J. Howerton, et. al., OMEGA, A CRAY 1 Executive Code for LLNL Nuclear Data Libraries Lawrence Livermore National Laboratory, Livermore, CA, UCRL-50400, Vol. 25 (1983). See specifically Ch. I and II.

3) D. E. Cullen, et. a., Tables and Graphs of Photon-Interaction Cross Sections Derived from the LLNL Evaluated Photon Data Library (EPDL). $\mathrm{Z}=1$ - 50, Lawrence Livermore National Laboratory, Livermore, CA, Vol. 6, Part A, Rev. 4 (1991).

4) D. E. Cullen, et. al., Tables and Graphs of Photon-Interaction Cross Sections Derived from the LLNL Evaluated Photon Data Library (EPDL) $Z=51-100$, Lawrence Livermore National Laboratory, Livermore, CA, Vol. 6, Part B: Rev. 4 (1991).

5) D. E. Cullen, S. T. Perkins, and J. A. Rathkopf, The 1989 Livermore Photon Data Library (EPDL), Lawrence Livermore National Laboratory, Livermore, CA, UCRLID-103424 (1990). 
6) S. T. Perkins, et. al., Tables and Graphs of Atomic Subshell and Relaxation Data Derived from the LLNL Evaluated Atomic Data Library (EADL), $Z=1-100$, Lawrence Livermore National Laboratory, Livermore, CA, Vol. 30 (1991).

7) D. E. Cullen, J. H. Hubbell, and L. Kissel, EPDL97: the Evaluated Photon Data Library, '97 Version, Lawrence Livermore National Laboratory, UCRL--50400, Vol. 6, Rev. 5, September 1997. 


\section{ENDL Type Formats for the Evaluated Photon Data Library (EPDL)}

\section{Contents}

This report describes the input formats for the Lawrence Livermore Evaluated Photon Data Library, EPDL ${ }^{1,2,3}$, the current version is identified as EPDL $97^{7}$. Tables and graphs of these data have been reported in ref. (1) and (2) and the evaluation process is discussed in ref. (3). These formats are an extension of the ENDL concepts which form the basis for Lawrence Livermore National Laboratory's evaluated data libraries. ${ }^{4}$

EPDL contains complete information for particle transport for $Z=1-100$. Earlier versions of EPDL contained data for incident photons energies from $10 \mathrm{eV}$, or threshold, to 100 $\mathrm{GeV}$. The 1997 release of EPDL (EPDL97) extended the incident photon energy range down to $1 \mathrm{eV}$. Units are barns and $\mathrm{MeV}$ (millions of electron volts). The specific data are the following:

1) Coherent scattering,

a) integrated cross section (b),

b) form factor,

c) real and imaginary anomalous scattering factors,

d) average energy of the scattered photon $(\mathrm{MeV})$,

2) Incoherent scattering

a) integrated cross section (b),

b) scattering function,

c) average energy of the scattered photon and recoil electron $(\mathrm{MeV})$.

3a) Total photoelectric reaction

a) integrated cross section (b),

b) average energy to the residual atom, i.e., local deposition (MeV),

c) average energy of the secondary photons and electrons $(\mathrm{MeV})$.

3b) Photoelectric reaction, by subshell

a) integrated cross section (b),

b) average energy to the residual atom, i.e., local deposition (MeV),

c) average energy of the secondary photons and electrons $(\mathrm{MeV})$.

4) Pair production reaction

a) integrated cross section (b),

b) average energy of the secondary electron and positron $(\mathrm{MeV})$.

5) Triplet production reaction

a) integrated cross section (b),

b) average energy of the secondary electron and positron $(\mathrm{MeV})$. 
In the context of particle transport, the EPDL file only contains data for photon transport. In order to perform coupled photon-electron transport calculations, two additional libraries are required. These are the Livermore Evaluated Electron Data Library (EEDL) ${ }^{5}$, which describes the interaction of electrons with matter, and the Livermore Evaluated Atomic Data Library (EADL) ${ }^{6}$, which describes atomic relaxation.

The photoelectric data in EPDL are only for photo-ionization, and does not include photo-excitation; photo-excitation data is now distributed with EPDL as a separate library named EXDL (the Evaluation eXcitation Data Library). Photo-ionization edges in EPDL97 may differ from those in other tabulations (e.g., NIST ${ }^{8}$, and LNL $^{9}$ ), due to value judgments or that other tabulations do not separate ionization and excitation. For our applications what's important is that edges are consistent between the three libraries: EADL, EEDL and EPDL. As stated earlier, for use in photon transport applications we judge consistency to be much more important than the absolute values of the edge energies.

In Section II, formats and definitions for the EPDL parameters are given. This is followed in Section III by the definitions, formats, and sorting order for the data in the EPDL file. In Section IV, the subshell designators are defined. Finally in Section V, several examples are given.

\section{Formats and Definitions for the EPDL Parameters}

All data are in the Livermore ENDL (Evaluated Nuclear Data Library) format ${ }^{4}$. Although the ENDL format is much more detailed, in this report only the definitions pertinent to the EPDL file are given. The data are in a series of character tables. Each table starts with two header lines that contain the parameters that physically describe the data that follow. The two header lines are followed by a series of data lines, one data point per line. Each table is terminated by an end of table line which is blank except for a 1 in column 72 (column 72 is blank on all other lines in the table). A table may be followed by another table or an end of file.

The two header lines in general in the ENDL format contain a great deal of information. However, as applied to the EPDL photon data the only fields of interest are as shown in Table I.

Table I. Header Line Formats for the EPDL Character File

\begin{tabular}{llll}
\hline Line & Columns & Format & Definition \\
\hline 1 & $1-3$ & I3 & Z - atomic number \\
1 & $4-6$ & I3 & A - mass number (in all cases=0, for \\
1 & $8-9$ & I2 & Yi - incident particle designator (see Table II) \\
1 & $11-12$ & I2 & Yo - outgoing particle designator (see Table II) \\
1 & $14-24$ & E11.4 & AW - atomic mass (amu)
\end{tabular}




\begin{tabular}{|c|c|c|c|}
\hline $26-31$ & I6 & Date - & date of evaluation (YYMMDD) \\
\hline 32 & I1 & Iflag - & interpolation flag \\
\hline & & & $=0$ or 2 , linear in $\mathrm{x}$ and $\mathrm{y}$ \\
\hline & & & $=3$, logarithmic in $x$, linear in $y$ \\
\hline & & & $=4$, linear in $\mathrm{x}$, logarithmic in $\mathrm{y}$ \\
\hline & & & $=5, \log$ arithmic in $\mathrm{x}$ and $\mathrm{y}$ \\
\hline $1-2$ & $\mathrm{I} 2$ & $\mathrm{C}$ & reaction descriptor (see Table II) \\
\hline $3-5$ & $\mathrm{I} 3$ & I & reaction property (see Table II) \\
\hline $6-8$ & $\mathrm{I} 3$ & $\mathrm{~S}$ & reaction modifier (see Table II) \\
\hline $22-32$ & E11.4 & $\mathrm{X} 1-$ & subshell designator (see Table VI) \\
\hline
\end{tabular}

Table II defines the ENDL parameters that are on the header lines. The actual values for these parameters are what classifies the data in the EPDL file.

\section{Table II. Definition of the EPDL Parameters}

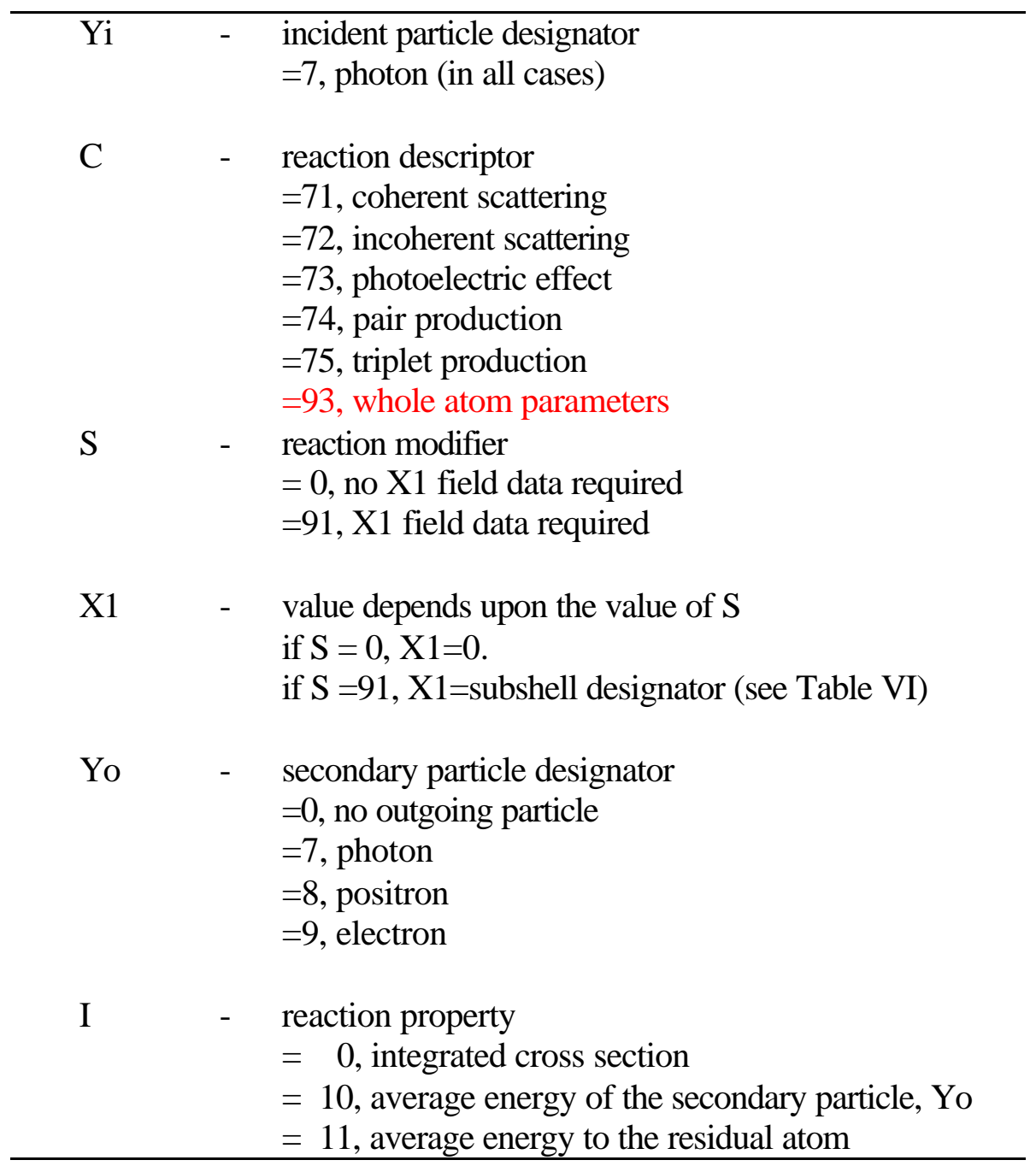


$=941$, form factor

$=942$, scattering function

$=943$, imaginary anomalous scattering factor

$=944$, real anomalous scattering factor

In Table III, a summary of the contents of the EPDL file is given in terms of the EPDL parameters.

Table III. Summary of the EPDL Data Base

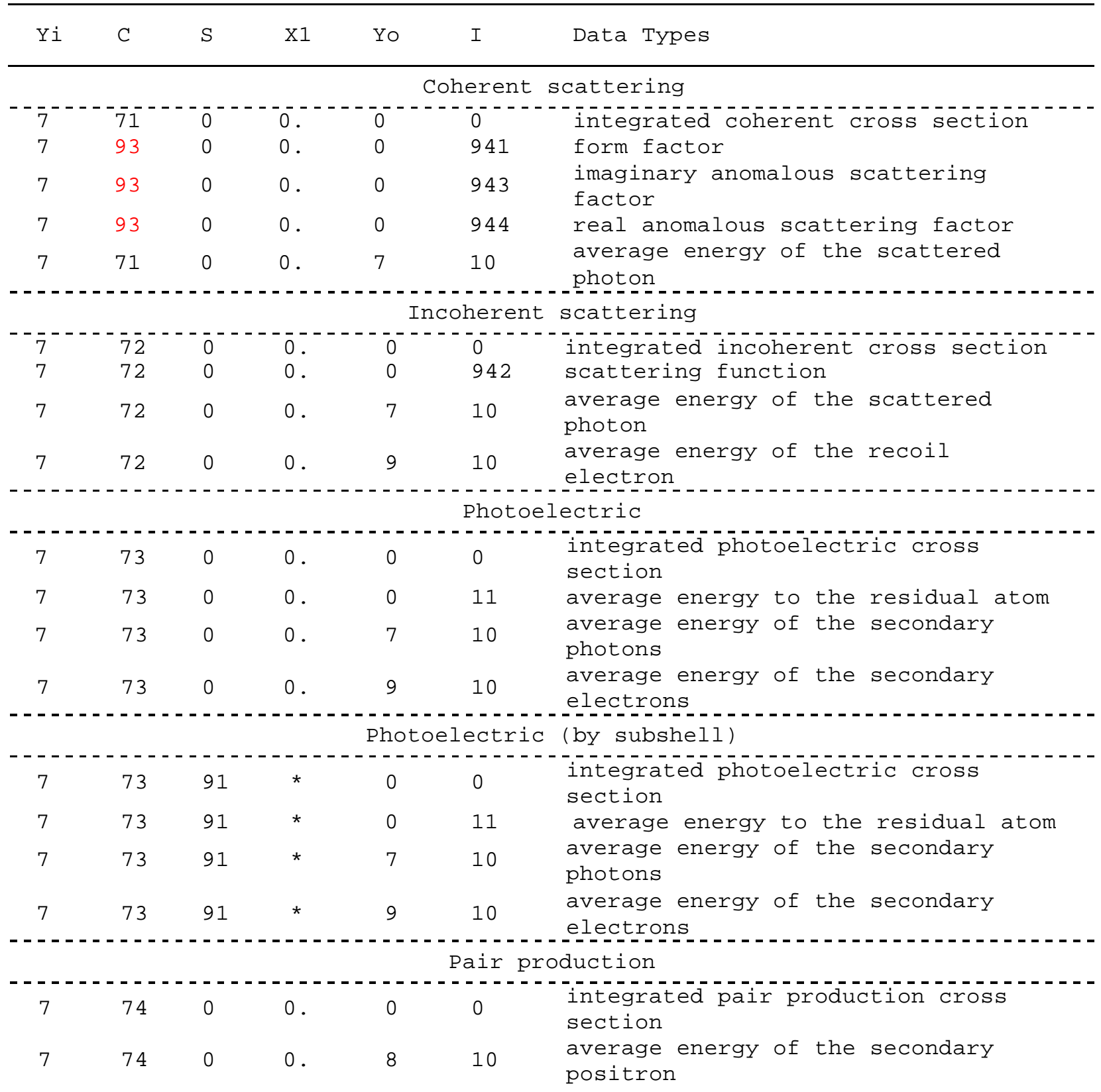




\begin{tabular}{|c|c|c|c|c|c|c|}
\hline 7 & 74 & 0 & 0 . & 9 & 10 & $\begin{array}{l}\text { average energy of the secondary } \\
\text { electron }\end{array}$ \\
\hline \multicolumn{7}{|c|}{$\begin{array}{r}\text { Triplet prodiction } \\
\quad\end{array}$} \\
\hline 7 & 75 & 0 & 0. & 0 & 0 & $\begin{array}{l}\text { integrated triplet production cros } \\
\text { section }\end{array}$ \\
\hline 7 & 75 & 0 & 0. & 8 & 10 & $\begin{array}{l}\text { average energy of the secondary } \\
\text { positron }\end{array}$ \\
\hline 7 & 75 & 0 & 0. & 9 & 10 & $\begin{array}{l}\text { average energy of the secondary } \\
\text { electron }\end{array}$ \\
\hline
\end{tabular}

${ }^{*}$ Subshell designator (see Table VI).

\section{Definitions and Formats for the EPDL Data Lines and Sorting Order}

The definitions for the data lines are described in Table IV, followed by their formats in Table V. This is followed by the sorting order of all of the data in the file.

The general ENDL data format defines some 35 types of reaction properties and is used to describe neutron, charged particle, photon, electron, positron, and atomic relaxation processes. The EPDL data definitions are but a small subset of this, as shown here.

\section{Table IV. Definitions of the EPDL Data}

\begin{tabular}{lll}
\hline $\mathrm{E}$ & - & incident photon energy \\
$\sigma$ & - & cross section \\
$\left\langle\mathrm{E}_{\mathrm{p}}^{\prime}\right\rangle$ & - & average energy of the secondary particle \\
$\left\langle\mathrm{E}_{\mathrm{loc}}\right\rangle$ & - & average energy to the residual atom, i.e., local deposition \\
$\mathrm{X}$ & - & argument for form factor and scattering function \\
$\mathrm{F}$ & - & coherent scattering form factor \\
$\mathrm{S}$ & - & incoherent scattering function \\
$\mathrm{I}$ & - & imaginary anomalous coherent scattering factor \\
$\mathrm{R}$ & - & real anomalous coherent scattering factor \\
\hline $\mathrm{a}$ & the parameter $\mathrm{x}\left(\mathrm{cm}^{-1}\right)$ is defined by $\mathrm{x}=\sin (\theta / 2) / \lambda$, where $\theta$ is the photon \\
& scattering angle and $\lambda$ is its wave length $(\mathrm{cm})$.
\end{tabular}

By definition for photon scattering, the average energy for the coherently scattered photon is equal to the energy of the incident photon. These values are carried in the data files so as not to make any special unique cases. For the photoelectric effect, photons and electrons are released from the atom. These are accounted for in energy deposition through the atom relaxation data from ref. (6). The average energy to the residual atom insures energy conservation and is deposited locally.

The format for the full ENDL data line is 6E11.4. However, the actual number of fields used (up to 6 maximum) depends explicitly upon the reaction property designator, I. Following each set of data is an end of table line with a 1 in column 72, i.e., format of 71X,I1. 
Table V. Actual formats for the EPDL Data Lines in Terms of the Reaction Property, I (see Table IV for definitions)

\begin{tabular}{llllll}
\hline I & \multicolumn{2}{l}{ Field Number (6E11.4 format) } & 4 & 5 & 6 \\
& 1 & 2 & 3 & 4 & \\
\hline 0 & E & $\sigma$ & & & \\
10 & E & $\left\langle\mathrm{E}_{\mathrm{p}}^{\prime}\right\rangle$ & & \\
11 & $\mathrm{E}$ & $\left\langle\mathrm{E}_{\mathrm{loc}}\right\rangle$ & & \\
941 & $\mathrm{X}$ & $\mathrm{F}$ & & \\
942 & $\mathrm{X}$ & $\mathrm{S}$ & & \\
943 & $\mathrm{E}$ & $\mathrm{I}$ & & \\
944 & $\mathrm{E}$ & $\mathrm{R}$ & & \\
\hline
\end{tabular}

The EPDL data is sorted in the following order for the character file:

The data is sorted into ascending order by $\mathrm{Z}(\mathrm{Z}=\mathrm{l}-100)$.

Within each $Z$, data is sorted by increasing $C$ number $(C=71-93)$.

Within each $\mathrm{C}$ number, data is sorted by increasing $\mathrm{S}$ number $(\mathrm{S}=0$ or 91 ).

Within each $\mathrm{S}$ number, data is sorted by increasing $\mathrm{X} 1$ field $(\mathrm{x} 1=1 .-61$.).

Within each $\mathrm{X} 1$ field, data is sorted by increasing Yo number $(\mathrm{Yo}=0-9)$.

Within each Yo number, data is sorted by increasing I number ( $\mathrm{I}=0-944)$.

Within each data block, data is sorted by increasing field number (see Table V) over all independent variables, i.e., the number of fields required for the data minus one. Field 1 is the slowest varying variable, field 2 the next slowest varying, etc.. For any variable, the sort is by increasing value, e.g., by increasing incident photon energy.

\section{Atomic Subshell Designator}

Atomic subshells in the ENDL format are specified by prescribed floating point designators. Although this description can specify shells, partial shells, and subshells, only the latter are used in the EPDL file. The designators are given in Table VI.

Table VI. Atomic Subshell Designators

\begin{tabular}{|c|c|c|c|c|c|c|c|}
\hline $\begin{array}{l}\text { Desig- } \\
\text { nator }\end{array}$ & & Subshell & $\begin{array}{l}\text { Desig- } \\
\text { nator }\end{array}$ & & Subshell & $\begin{array}{l}\text { Desig- } \\
\text { nator }\end{array}$ & Subshell \\
\hline 1. & $\bar{K}$ & $(1 \mathrm{~s} 1 / 2)$ & 21. & $\mathrm{~N} 4$ & $(4 \mathrm{~d} 3 / 2)$ & 41. & $\mathrm{Pl}(6 \mathrm{~s} 1 / 2)$ \\
\hline 2. & $\mathrm{~L}$ & (2) & 22. & N5 & $(4 \mathrm{~d} 5 / 2)$ & 42. & P23 (6p) \\
\hline 3. & $\mathrm{Ll}$ & $(2 \mathrm{~s} 1 / 2)$ & 23. & N67 & $(4 f)$ & 43. & $\mathrm{P} 2 \quad(6 \mathrm{p} 1 / 2)$ \\
\hline 4. & L23 & $(2 p)$ & 24. & N6 & $(4 f 5 / 2)$ & 44. & P3 (6p3/2) \\
\hline 5. & $\mathrm{~L} 2$ & $(2 \mathrm{p} 1 / 2)$ & 25. & N7 & $(4 \mathrm{f} 7 / 2)$ & 45. & $\mathrm{P} 45 \quad(6 \mathrm{~d})$ \\
\hline 6. & L3 & $(2 \mathrm{p} 3 / 2)$ & 26. & $\mathrm{O}$ & (5) & 46. & $\mathrm{P} 4 \quad(6 \mathrm{~d} 3 / 2)$ \\
\hline 7. & $\mathrm{M}$ & (3) & 27. & $\mathrm{O} 1$ & $(5 \mathrm{~s} 1 / 2)$ & 47. & P5 $(6 \mathrm{~d} 5 / 2)$ \\
\hline 8. & Ml & $(3 \mathrm{~s} 1 / 2)$ & 28. & $\mathrm{O} 23$ & $(5 p)$ & 48. & P67 (6f) \\
\hline
\end{tabular}




\begin{tabular}{|c|c|c|c|c|c|c|c|c|}
\hline 9. & M23 & $(3 p)$ & 29. & $\mathrm{O} 2$ & $(5 \mathrm{p} 1 / 2)$ & 49. & P6 & $(6 f 5 / 2)$ \\
\hline 10. & M2 & $(3 \mathrm{p} 1 / 2)$ & 30. & $\mathrm{O} 3$ & $(5 \mathrm{p} 3 / 2)$ & 50. & P7 & $(6 f 7 / 2)$ \\
\hline 11. & M3 & $(3 \mathrm{p} 3 / 2)$ & 31. & $\mathrm{O} 45$ & $(5 d)$ & 51. & P89 & $(6 \mathrm{~g})$ \\
\hline 12. & M45 & (3d) & 32. & $\mathrm{O} 4$ & $(5 \mathrm{~d} 3 / 2)$ & 52. & P8 & $(6 \mathrm{~g} 7 / 2)$ \\
\hline 13. & M4 & $(3 \mathrm{~d} 3 / 2)$ & 33. & O5 & $(5 \mathrm{~d} 5 / 2)$ & 53. & P9 & $(6 \mathrm{~g} 9 / 2)$ \\
\hline 14. & M5 & $(3 \mathrm{~d} 5 / 2)$ & 34. & O67 & $(5 f)$ & 54. & P1011 & (6h) \\
\hline 15. & $\mathrm{~N}$ & (4) & 35. & O6 & $(5 f 5 / 2)$ & 55. & P10 & $(6 \mathrm{~h} 9 / 2)$ \\
\hline 16. & $\mathrm{Nl}$ & $(4 \mathrm{~s} 1 / 2)$ & 36. & O7 & $(5 f 7 / 2)$ & 56. & P11 & $(6 \mathrm{~h} 11 / 2)$ \\
\hline 17. & $\mathrm{~N} 23$ & $(4 p)$ & 37. & O89 & $(5 \mathrm{~g})$ & 57. & Q & (7) \\
\hline 18. & $\mathrm{~N} 2$ & $(4 \mathrm{p} 1 / 2)$ & 38. & O8 & $(5 \mathrm{~g} 7 / 2)$ & 58. & Q1 & $(7 \mathrm{~s} 1 / 2)$ \\
\hline 19. & N3 & $(4 \mathrm{p} 3 / 2)$ & 39. & O9 & $(5 \mathrm{~g} 9 / 2)$ & 59. & Q23 & $(7 p)$ \\
\hline 20. & N45 & (4d) & 40. & $\mathrm{P}$ & (6) & 60. & Q2 & $(7 \mathrm{p} 1 / 2)$ \\
\hline & & & & & & 61. & Q3 & $(7 \mathrm{p} 3 / 2)$ \\
\hline
\end{tabular}

\section{Examples}

In this section, several examples of EPDL data are given. These may not coincide with the data in the existing file as improvements are continually being made. As described earlier, the data is in an E11.4 format, with the exception of machine independent modifications made to give more significant figures within the eleven columns. Note also that some of the data lines may have been deleted in order to condense the table to an acceptable size.

The first example is for incoherent scattering. There are two tables included here. The first is for the average energy to the scattered photon and the second is for the average energy to the recoil electron.

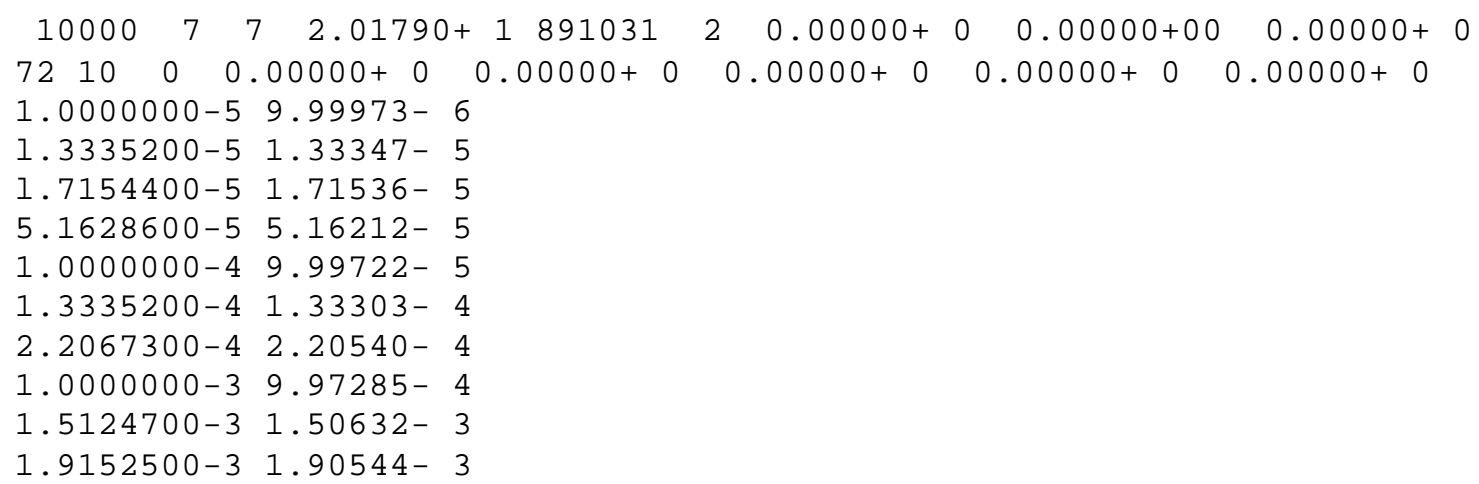


$1.00000+41.20394+3$

$1.00000+59.95532+3$

$10000792.01790+1891031 \quad 2 \quad 0.00000+0 \quad 0.00000+00 \quad 0.00000+0$ $721000.00000+00.00000+00.00000+0 \quad 0.00000+0 \quad 0.00000+0$ $1.0000000-5 \quad 2.74017-10$

$1.3335200-5 \quad 4.87716-10$

$1.7154400-5 \quad 8.11753-10$

$5.1628600-57.40653-9$

$1.0000000-42.78343-8$

$1.3335200-4 \quad 4.93021-8$

$2.2067300-4 \quad 1.33607-7$

$5.6742200-4 \quad 8.78699-7$

$1.0000000-32.71464-6$

$1.5124700-36.15721-6$

$1.9152500-39.81358-6$

$2.3547700-31.46577-5$

$2.8213400-3 \quad 2.08466-5$

$3.5579900-3 \quad 3.25158-5$

$4.2839800-3 \quad 4.63741-5$

$5.0042900-3 \quad 6.22147-5$

$5.9498600-38.59610-5$

$1.00000+16.83543+0$

$1.77828+11.28036+1$

$4.21697+13.21440+1$

$1.00000+27.93827+1$

$3.16228+22.60881+2$

$1.00000+38.47970+2$

$5.62341+34.90922+3$

$1.00000+48.79606+3$

$1.00000+59.00447+4$

The second example is for the photoelectric cross section of the $\mathrm{K}$ shell in neon $(\mathrm{Z}=10)$.

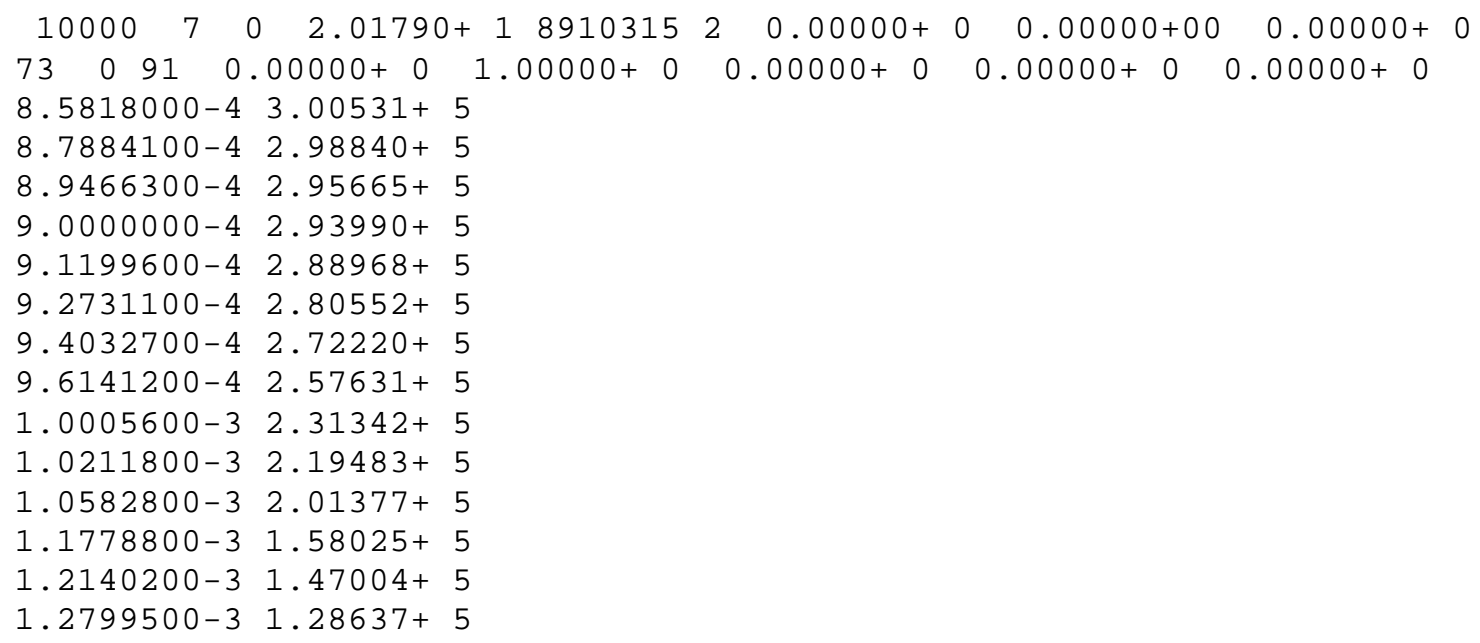


$8.00000+31.28280-8$

$1.00000+41.02586-8$

$1.50000+46.83907-9$

$2.00000+45.12930-9$

$3.00000+43.41953-9$

$4.00000+42.56465-9$

$5.00000+42.05172-9$

$6.00000+41.70977-9$

$8.00000+41.28185-9$

$1.00000+51.02586-9$

\section{References}

1) D. E. Cullen, et. al., Tables and Graphs of Photon-Interaction Cross Sections Derived from the LLNL Evaluated Photon Data Library (EPDL), Z = 1 - 50, Lawrence Livermore National Laboratory, Livermore, CA, Vol. 6, Part A, Rev. 4 (1991).

2) D. E. Cullen, et. al., Tables and Graphs of Photon-Interaction Cross Sections Derived from the LLNL Evaluated Photon Data Library (EPDL), Z = 51 - 100, Lawrence Livermore National Laboratory, Livermore, CA, Vol. 6, Part B, Rev. 4 (1991).

3) D. E. Cullen, S. T. Perkins, and J. A. Rathkopf, The 1989 Livermore Photon Data Library (EPDL), Lawrence Livermore National Laboratory, Livermore, CA, UCRLID-103424 (1990).

4) R. J. Howerton, et. al., OMEGA. A CRAY 1 Executive Code for LLNL Nuclear Data Libraries, Lawrence Livermore National Laboratory, Livermore, CA, UCRL-50400, Vol. 25 (1983). See specifically Ch. I and II.

5) S. T. Perkins, D. E. Cullen, and S. M. Seltzer, Tables and Graphs of ElectronInteraction Cross Sections Derived from the LLNL Evaluated Electron Data Library (EEDL), $Z=1-100$, Lawrence Livermore National Laboratory, Livermore, CA, Vol. 31 (1991).

6) S. T. Perkins, et. al., Tables and Graphs of Atomic Subshell and Relaxation Data Derived from the LLNL Evaluated Atomic Data Library (EADL), $\mathrm{Z}=1-100$, Lawrence Livermore National Laboratory, Livermore, CA,.Vol. 30 (1991).

7) D. E. Cullen, J. H. Hubbell, and L. Kissel, EPDL97: the Evaluated Photon Data Library, 97 Version, Lawrence Livermore National Laboratory, UCRL--50400, Vol. 6, Rev. 5, September 1997.

8) see the NIST website, http://physics.nist.gov/PhysRefData/contents.html

9) see the LBL website, http://www-cxro.lbl.gov/optical_constants 